\title{
Cross-cultural adaptation of the Preterm Parenting \& Self-efficacy Checklist
}

\author{
Adaptação transcultural do Preterm Parenting \& Self-Efficacy Checklist \\ Adaptación transcultural de Preterm Parenting \& Self-efficacy Checklist
}

\section{Carolina Queiroz de Souza Mendes' \\ ORCID: 0000-0002-8408-6408}

Myriam Aparecida Mandetta' ORCID: 0000-0003-4399-2479

Miriam Harumi Tsunemi" ORCID: 0000-0002-9585-4230

Maria Magda Ferreira Gomes Balieiro' ORCID: 0000-0002-4367-5855

'Universidade Federal de São Paulo. São Paulo, São Paulo, Brazil. "Universidade Estadual Paulista Julio de Mesquita Filho. Botucatu, São Paulo, Brazil.

How to cite this article: Mendes CQS, Mandetta MA, Tsunemi MH, Balieiro MMFG. Cross-cultural adaptation of the Preterm Parenting \& Selfefficacy Checklist. Rev Bras Enferm. 2019;72(Suppl 3):274-81. doi: http://dx.doi.org/10.1590/0034-7167-2018-0658

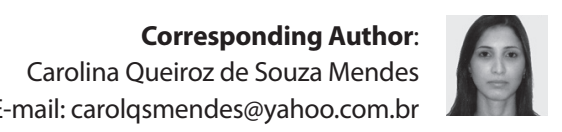

Submission: 09-05-2018 Approval: 11-06-2018

\begin{abstract}
Objective: To conduct a cross-cultural adaptation of the Preterm Parenting \& Self-Efficacy Checklist to the Brazilian Portuguese. Method: A methodological study was carried out with 51 parents of premature infants. Data analysis was based on psychometric and inferential statistical analyses. Results: The instrument content validation by experts obtained excellent agreement (97\%) and the semantic analysis by the target population showed good understanding of the terms and ease of use. In test-retest, most participants were female (64.7\%); and parents with higher education (47.1\%). The instrument showed stability over time, with good internal consistency $(a=0.84)$. Four factors were generated in the subscales parenting self-efficacy, importance of tasks and self-perceived parental competence (67.0\% to $74.2 \%$ of the variance). Conclusion: The properties of the Preterm Parenting \& Self-Efficacy Checklist - Brazilian Version were maintained, which is a reliable indicator to evaluate the hospital discharge of premature infants.

Descriptors: Self-efficacy; Parents; Infant, Premature; Validation Studies; Neonatal Nursing.
\end{abstract}

\section{RESUMO}

Objetivo: Realizar a adaptação transcultural do Preterm Parenting \& Self-Efficacy Checklist para o português brasileiro. Método: Estudo metodológico, realizado com 51 pais de recémnascidos prematuros. A análise dos dados utilizou-se da psicometria e da estatística inferencial. Resultados: A validação de conteúdo do instrumento pelos especialistas obteve concordância excelente (97\%), e a análise semântica com a população-alvo demonstrou compreensão dos termos e facilidade na sua utilização. No teste-reteste, houve maioria de participantes do sexo feminino $(64,7 \%)$ e de pais com ensino superior $(47,1 \%)$. $O$ instrumento apresentou estabilidade ao longo do tempo, com boa consistência interna $(\alpha=0.84)$. Quatro fatores foram gerados nas subescalas "autoeficácia parental", "importância das tarefas" e "competência parental autopercebida" (67,0\% a 74,2\% da variância). Conclusão: Houve a manutenção das propriedades do Preterm Parenting \& Self-Efficacy Checklist - Versão Brasileira, que se configura como um indicador confiável para avaliar a alta hospitalar do prematuro.

Descritores: Autoeficácia; Pais; Recém-Nascido Prematuro; Estudos de Validação; Enfermagem Neonatal.

\section{RESUMEN}

Objetivo: Realizar la adaptación transcultural de Preterm Parenting \& Self-Efficacy Checklist para el portugués de Brasil. Método: Estudio metodológico, en el cual participaron 51 padres de recién nacidos prematuros. En el análisis de datos se utilizaron la psicometría y la estadística inferencial. Resultados: La validación de contenido del instrumento por los expertos obtuvo una concordancia excelente (97\%), y el análisis semántico con la población demostró comprensión de los términos y facilidad en su utilización. En el test-retest, hubo la mayoría de participantes del sexo femenino (64,7\%); y de padres con enseñanza superior $(47,1 \%)$. El instrumento fue estable a lo largo del tiempo, presentando una buena consistencia interna $(a=0.84)$. Se generaron cuatro factores en las subescalas: autoeficacia parental; importancia de las tareas; $y$ competencia parental autopercibida (del $67,0 \%$ al $74,2 \%$ de la varianza). Conclusión: Las propiedades de Preterm Parenting \& SelfEfficacy Checklist -versión brasileña- se mantuvieron, lo que configura como un indicador fiable de evaluación del alta hospitalaria del prematuro.

Descriptores: Autoeficacia; Padres; Recién Nacido Prematuro; Estudios de Validación; Enfermería Neonatal. 


\section{INTRODUCTION}

Preterm birth causes a feeling of frustration in parents due to separation from the newborn, altering the family dynamics. A preterm birth may cause a family crisis because of long-term changes in the family routine and constant contact with a frequently stressful environment for the parents and for the premature infant related to the aspect, behavior and health condition of the newborn, to the use of many technological resources, to the need of interaction with several health professionals, and to the philosophy of this service, which is restrictive to the family's participation ${ }^{(1-2)}$.

All these elements may be an obstacle to the development of parenting skills which is defined as the way in which feelings, functions and behaviors are built while performing motherhood and parenthood roles, and whose practice refers to physical and psychological care and daily tasks parents perform with their child $^{(3)}$. Therefore, those parents who participate in their child care and remain by their side feel they are better prepared for the transition from hospital to home ${ }^{(4-5)}$.

Health professionals, especially nurses, need to develop strategies to promote family well-being and strengthen the bond between the parents and the newborn ${ }^{(5-6)}$. In this sense, one useful strategy refers to helping parents build self-confidence in providing care to their premature infant, since hospitalization, so that they can achieve independence in child care after hospital discharge $\mathrm{e}^{(1,7-8)}$.

Parental self-confidence results from the parents'belief in their selfefficacy in child care. The concept of parental self-efficacy is based on the social cognitive theory of self-regulation proposed by Bandura( ${ }^{(9)}$, defined as'beliefs or judgments parents hold of their capabilities to organize and execute a set of tasks related to parenting a child'(10).

The parental confidence assessment in child care has important clinical and research applications in health care settings. However, a lack of instruments that evaluate this construct is observed in Brazil. In a literature review, nine instruments were identified for the measurement of confidence, beliefs and capacities and selfefficacy of parents. Of these, three referred to preterm infants, but only the Preterm Parenting \& Self-Efficacy Checklist ${ }^{(11)}$ addressed parents outside the hospital setting.

This instrument was developed in Australia, and consists of 36 questions, aiming to measure parental self-efficacy in tasks of care for preterm infant and newborn full term. The questions are grouped into three subscales that measure parental self-efficacy (beliefs and judgments that parents hold to organize and perform tasks related to child care); the importance of tasks (how important parents feel in a particular task); and self-perceived parental competence (abilities that parents have to perform a given task). For the answers, a 7-point Likert scale is used (1-Not confident at all; 2-Not confident; 3-Not very confident; 4-Insecure; 5-Little confident; 6-Confident; 7-Very confident), and seven questions have a'not applicable' answer, as these situations may or may not be part of that family, such as having other children ${ }^{(11)}$. Then, the validation of the Preterm Parenting \& Self-Efficacy Checklist in Brazilian Portuguese is questioned in terms of whether or not it presents the properties of the original instrument.

\section{OBJECTIVE}

To conduct a cross-cultural adaptation of the Preterm Parenting \& Self-Efficacy Checklist to the Brazilian Portuguese language.

\section{METHOD}

\section{Ethical aspects}

The authors of the original instrument were contacted via electronic means to request authorization for a cross-cultural adaptation of the instrument to Brazilian Portuguese. Then, the approval was obtained from the Research Ethics Committees, protocols 1.621 .522 and 07/15.

National and international recommendations (CNS Resolution $n^{\circ} .466 / 12$ ) of research involving human beings were followed, ensuring participant anonymity, confidentiality and the possibility of dropping out at any time. An informed consent form was signed by all participants in all study stages, provided in two counterparts.

\section{Study design, local and period}

This is a methodological study of cross-cultural adaptation of a measurement instrument, according to the stages proposed by Guillemin, Bombardier, Ferraz and Beaton ${ }^{(12)}$. These stages are: initial translation, synthesis of translations, back translation, review by a committee of experts, pre-test/test-retest of the final version, and psychometric analyses ${ }^{(12-13)}$ (Figure 1). Data collection of the study was performed from June 2016 to November 2017.

The study was performed at a private hospital with characteristics of maternity and neonatal care located in the south area of the city of Sao Paulo. Its neonatal intensive care unit (NICU) is composed of six units: a surgical unit, a long-term hospitalization unit, two units for high-risk newborn, a unit for intermediate care, and a semi-intensive unit. Parents can access the NICU 24 hours a day; during premature infant admission, parents receive instructions for care, and hospital discharge is planned jointly by the multidisciplinary health team.

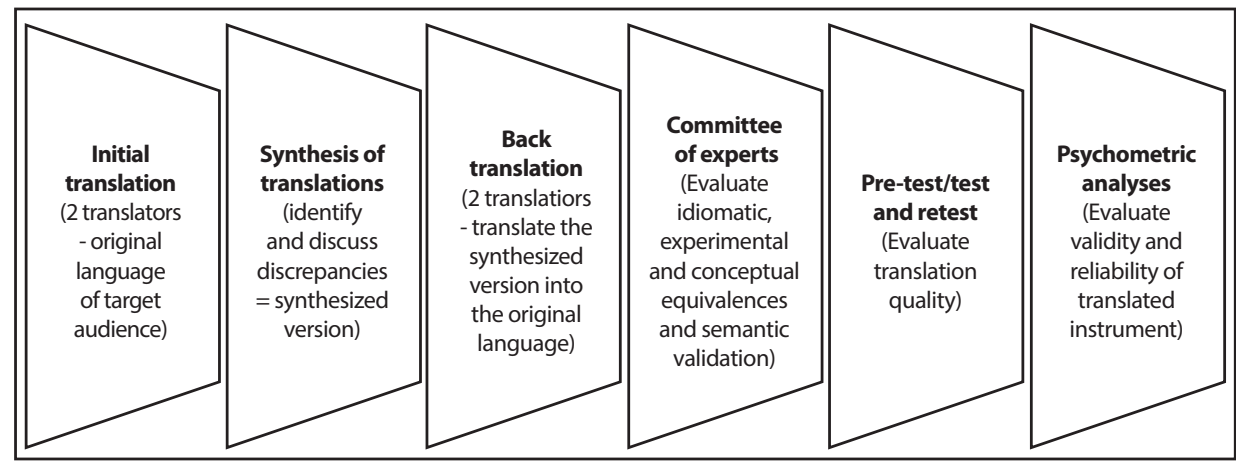

Figure 1 - Steps of cross-cultural adaptation 


\section{Study population and sample}

The initial translation of the Preterm Parenting \& Self-Efficacy Checklist was performed by a medical translator who was informed about the study purpose and another translator from the administration area, who was not aware of the study purpose; both were fluent in English, with Brazilian Portuguese proficiency. In the back translation stage, the synthesized version was translated by two independent translators, one was American and one was Australian, both fluent in Brazilian Portuguese, with English proficiency; and who were not aware of the original instrument, study purpose and who did not communicate during this stage.

The Committee of Experts was composed of seven health professionals with knowledge on newborn care in neonatal unit and family care, with master's and doctor's degrees; who met the criteria of expert classification according to the Fehring Validation Model ${ }^{(14)}$, adapted to this study with scores of five or above.

For the semantic validation stage, the adapted version of the instrument was submitted to a sample of eight parents of preterm infants from the NICU of the study site and who did not participate in the other study stages.

For the pre-test and test-retest stages, the final sample consisted of 51 parents of premature infants eligible for the study, according to the criteria described below.

The sample calculation of these stages followed the recommendations of Guillemin, Bombardier, Ferraz and Beaton ${ }^{(12)}$ for validation studies, which considers a sample of at least 50 participants.

\section{Inclusion and exclusion criteria}

For the semantic validation, pre-test and test-retest stages, the inclusion criteria were: parents or legal guardians of a preterm infant, gestational age of 28 to 36 weeks and 6 days, clinically stable breastfed preterm infants, with scheduled hospital discharge. The exclusion criteria were: parents of newborns with a congenital anomaly; and parents of newborns who had a gastric probe, submitted to gastrostomy, receiving supplemental oxygen and medications of multiple daily doses, and parents of twin newborns, if they were not discharged on the same day.

\section{Study protocol}

In the translation stage of the Preterm Parenting \& Self-Efficacy Checklist, the two translators did not communicated each other. Both performed independent translations that were sent to the researchers, along with a report describing challenges they had while adapting some terms to Brazilian Portuguese. A synthesized version was produced by the researchers, resulting in the Translated Version of the Preterm Parenting \& Self-Efficacy Checklist.

In the back translation stage, they translated the synthesized version of the instrument, with some changes in terms and phrases for better adaptation.

The evaluation of the synthesized version of the translation aiming to produce the final instrument for the test-retest phase used the Delphi technique, the content validity index (CVI) and the level of agreement through an instrument produced by the researchers with a 3-point Likert scale: 1-Agree, 2-Do not agree or disagree, 3-Disagree, and a field for suggestions.

After approval by the Committee of Experts, the Preterm Parenting \& Self-Efficacy Checklist - Version 3 was submitted to a semantic validation. In this stage, a questionnaire was developed of four sections of nine questions each, with 3-point Likert answers to evaluate relevance: 1-Essential, 2-Useful, but not essential, 3-Unnecessary; clarity of questions: 1-I totally agree, 2-I do not agree or disagree, 3-I do not agree; and difficulty of use: 1-Not difficult, 2-Little difficult, 3-Very difficult. A field was provided for respondents to give suggestion regarding the instrument questions. In addition, a socio-demographic background questionnaire was answered by the participants.

The study variables were: socio-demographic characteristics of participants; clinical perinatal and neonatal characteristics of the mother and infant; and perception of parental self-efficacy in premature newborn care, measured by the application of Preterm Parenting \& Self-Efficacy Checklist - Version 3.

The participants were approached during the hospitalization of premature newborns with scheduled hospital discharge. The first approach was often to mothers due to infant long-term hospitalization and the father's return to work. The first data collection took place 3 days after hospital discharge and the second data collection, 96 hours after the first collection, since this period was necessary for the parents to perform certain tasks. The second contact with the study participants was by mobile phone to remind them of the research goals and reinforce the importance of their participation.

In the pre-test and test-retest stage, the questionnaire of sociodemographic characteristics of the participant and the family was applied, the form of perinatal and neonatal characteristics was filled out, and the instrument adapted, translated and approved by the Committee of Experts and the target population were applied, inserted in the RedCap ${ }^{\mathrm{TM}}$ program.

Data were collected by the participants via electronic means and mobile phone. The form was filled out with perinatal and neonatal characteristics by the researcher after checking the medical records of newborns.

\section{Analysis of results and statistics}

Data were analyzed by descriptive and inferential statistics. Cronbach's alpha coefficient was used to determine the internal consistency of the instrument and correlations between the items and for the items of each domain or subscale ${ }^{(13,15)}$.

In the test-retest stage, the agreement between the questions in the first and second application of the instrument (stability and reproducibility) was evaluated by the intraclass correlation coefficient (ICC), which estimates the fraction of total variability of measurements among individuals ${ }^{(13,15)}$.

A factor analysis was conducted for construct validity, after confirmation of the Kaiser-Meyer-Olkin (KMO) test and the Bartlett's test ${ }^{(15-16)}$.

In the factor analysis, values above 0.60 were considered as very good and statistically significant. To determine the quantity of factors to be extracted, the criterion of cumulative variance was adopted, which considers $60 \%$ as an acceptable level(16). 
The method of principal components of independent rotation through Varimax was used to maximize the sum of the variances of the factor loading matrix ${ }^{(15)}$.

The Wilcoxon, Mann-Whitney, and Spearman tests were used to verify the associations among variables. For the descriptive analysis of the variables and the assumption of normality, the Kolmogorov-Smirnov test was performed ${ }^{(17)}$.

Equality of two proportions was also applied; it is a non-parametric test that compares if the proportion of the answers from two given variables and/or their levels is statistically significant. The result of each comparison has a measure called $p$-value, which evaluates the significance of the comparison ${ }^{(15)}$. The level of significance adopted for the tests was $5 \%(p=0.005)$ and SPSS 17.0 and a Microsoft Excel spreadsheet were used in statistical analyses.

\section{RESULTS}

In the translation stage, the two independent participants submitted their translations for analysis and production of the synthesized version, Version 1 of the Preterm Parenting \& SelfEfficacy Checklist. In the back translation, the native translators changed the original version into the following items: in the introduction of the instrument, the sentence "Kindly read and answer all the questions carefully" was replaced with "Please read and answer all questions carefully," as they thought "kindly" and "carefully" together were exaggerated, so they decided to keep "carefully"; in question 24, in the sentence "How successful do you think you were at using baby safe methods?", the word "safe" was replaced with "safety."This term was considered more adequate as the intention was to refer to safety methods. The question was back translated as: "How successful do you think you were at using baby safety methods?"

After the changes were suggested and approved, the Back Translated Version of the Preterm Parenting \& Self-Efficacy Checklist was generated, which was sent, along with the Brazilian Portuguese version, to the main author of the original instrument to check for adequacy of the concepts to the original version. The author approved it without any change.

Version 1 of the instrument was submitted to three rounds of evaluation by the Committee of Experts, resulting in Version 3, which was approved with $97 \%$ level of agreement and 0.97 $\mathrm{CVI}$, indicating good representativeness of the instrument items.

The semantic validation of the Preterm Parenting \& Self-Efficacy Checklist with the target population was conducted with eight participants - three male and five female participants, mean age of 34.3 years; most of them were white, married, with higher education and employed. The most frequent occupation was teacher. In this stage, the participants considered the instrument questions as relevant, clear and not difficult to use. Understanding of terms was $100 \%$ among the representatives of the target population. One participant suggested reducing items from the Likert scale from seven points to five points (1-Not confident at all, 2-Insecure, 3-Little confident, 4-Confident, 5-Very confident); however, this suggestion was not accepted by the authors of this study. Then, the instrument had no changes for the next empirical stage of pretest and test-retest, constituting the Preterm Parenting \& Self-Efficacy Checklist - Version 3.
The empirical stage of the cross-cultural adaptation of this instrument (pre-test and test-retest) had 51 participants, most of them $(33 ; 64.7 \%)$ were female; white $(33 ; 64.7 \%)$ and married $(49 ; 96.1 \%)$. The most frequent schooling level was higher education ( $24 ; 47.1 \%) ; 18$ worked in the administration field (35.3\%), 42 were currently employed $(82.4 \%)$, and 8 had previous experience with premature child (15.7\%). The mean age of the parents was $33.37( \pm 6.29)$ and the number of people living in the house was $3.29( \pm 0.97)$.

In relation to the support received by the family regarding the care for the NB, the mother was the main caregiver in the morning $(42 ; 82.4 \%)$, afternoon $(39 ; 76.5 \%)$ and night $(37 ; 72.5 \%)$; with the father support at night $(30,58.8 \%)$ and other family members in the afternoon $(24 ; 47.1 \%)$.

At hospital discharge, the most frequent information received by the parents was about hygiene $(51 ; 100 \%)$, vaccines $(50$; $98.0 \%)$, breastfeeding $(49 ; 96.1 \%)$, proper sleeping position of the newborn, and follow-up visit to pediatrician (48; $94.1 \%$ for each).

Regarding the professionals who provided guidance at hospital discharge, the physician was mentioned more frequently (47; $92.2 \%)$, followed by the nurse and other members of the nursing team $(46 ; 90.2 \%)$. The most frequent means of receiving information at hospital discharge was verbal explanation (50;98.0\%), followed by a demonstration of newborn care by the health team.

Regarding the perinatal and neonatal variables, most newborns were male $(22,56.4 \%)$, born of single pregnancy $(34,91.9 \%)$ and through cesarean delivery $(33,89.2 \%)$. For the classification of prematurity, weight and weight-related gestational age, 19 newborns (48.7\%) were late preterm; $26(66.7 \%)$ presented low weight and 5 (12.8\%) very low weight. Also, 29 premature infants (74.4\%) had proper weight for the gestational age.

Mean gestational age of the neonates was $33( \pm 1.00)$ weeks and $2.77( \pm 2.17)$ days; mean birth weight of $2025.6 \mathrm{~g}( \pm 447.9)$; and mean period in the neonatal unit was $21.5( \pm 12.3)$ days. Mean fetal losses, neonatal death or abortion was $0.46( \pm 0.77)$, with median of previous pregnancy of 1.00 .

In relation to diagnosis of premature newborns at hospital discharge, the highest incidence was maternal risk factors (35; $89.7 \%)$, respiratory system complications $(35 ; 89.7 \%)$, followed by hematological complications $(33 ; 84.6 \%)$.

The application of the Preterm Parenting \& Self-Efficacy Checklist - Version 3 in the test-retest stage identified an ICC of 0.062 in the three subscales, indicating low stability over time. When analyzing the ICC of each question of the instrument, 13 questions did not present reliability for stability in the test-retest. In the other variables, the correlations were statistically significant, that is, the reliability for stability over time was confirmed. As the instrument has three subscales - parental self-efficacy, importance of tasks and self-perceived parental competence - the authors decided to analyze the ICC by subscale and the resulting values were also low.

The Preterm Parenting \& Self-Efficacy Checklist - Version 3 presented good internal consistency of data in relation to the construct analyzed, with Cronbach's alpha of 0.840 for the instrument as a whole. In the subscales, Cronbach's alpha was 0.508 for parental self-efficacy, 0.644 for the importance of tasks, and 0.656 for self-perceived parental competence. In the analysis of 
the scale as a whole, considering the exclusion of items, Cronbach's alpha remained above 0.80 , which indicates good internal consistency of the instrument.

In the KMO test, the version 3 of the instrument obtained 0.561 , with $0.000 \mathrm{p}$-value according to the Bartlett test, which allowed the factor analysis as correlation was observed between the data of the instrument.

The results of the analysis by subscale showed that, in the KMO test, parental self-efficacy presented 0.779, $0.000 \mathrm{p}$-value according to the Bartlett's test, and cumulative variance of $74.1 \%$; importance of tasks presented $0.714,0.000 \mathrm{p}$-value and variance of $67.9 \%$; and self-perceived parental competence presented 0.741 , Bartlett's test with $\mathrm{p}=0.000$, and cumulative variance of $67.0 \%$. These values allowed the factor analysis as correlation was observed between the questions of each subscale.

Each subscale showed convergence in four factors (Table 1), with their largest load factor of 0.969 for parental self-efficacy; 0.863 for the importance of tasks; and 0.929 for self-perceived parental competence.

When analyzing the application of the third version of Preterm Parenting \& Self-Efficacy Checklist to the target population, participants perceived themselves as "little confident" (mean of 5.6) in being able to take care of their premature infant at home. In the subscale of parental self-efficacy, parents perceived themselves as "confident" (mean of 6.7) in providing care to their preterm infant. In the scale of importance of tasks, parents considered the tasks as important for the preterm infant care (mean of 6.0) after hospital discharge, in their parenting ability.

In the comparison of the mean values of the answers from participants and by sex (Table 2), statistical significance was observed in question 3 : Success in the bath $(p=0.032)$; question 16 : Confidence in diaper change ( $p=0.030)$; question 26: Importance in dealing with restlessness and crying $(p=0.001)$; question 29: Importance in understanding the signs of the newborn $(p=0.017)$ among the female participants.

In the correlation between the variables of respondent and newborn by subscale, statistical significance was observed in the subscale of importance of tasks with age $(p=0.025)$, marital status $(p=0.031)$ and weight $(p=0.002)$. For the subscale of self-perceived parental competence, correlations were observed with parents age $(p=0.004)$, marital status $(p=0.033)$, weight $(p=0.005)$ and hospitalization period $(p=0.047)$.

Table 1 - Factor analysis of the Preterm Parenting \& Self-Efficacy Checklist - Brazilian Version - by subscale, São Paulo, Brazil, 2018

\begin{tabular}{|c|c|c|c|c|c|}
\hline \multirow{2}{*}{\multicolumn{2}{|c|}{ Questions }} & \multicolumn{4}{|c|}{ Component } \\
\hline & & 1 & 2 & 3 & 4 \\
\hline 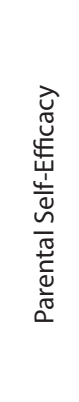 & $\begin{array}{l}\text { Q*.28 Confidence in understanding infant signs } \\
\text { Q.13 Confidence in safe sleeping methods } \\
\text { Q.19 Confidence in resuscitation } \\
\text { Q.22 Confidence in safe transportation } \\
\text { Q.25 Confidence in dealing with restlessness and crying } \\
\text { Q.16 Confidence in diaper change } \\
\text { Q.10 Confidence in providing infant health care } \\
\text { Q.1 Confidence in the bath } \\
\text { Q.7 Confidence in feeding the infant } \\
\text { Q.4 Confidence in calming down } \\
\text { Q.31 Confidence in the adaptation to the infant } \\
\text { Q.34 Confidence in caring with a partner as a team }\end{array}$ & $\begin{array}{l}0.834 \\
0.789 \\
0.783 \\
0.594 \\
0.583\end{array}$ & $\begin{array}{l}0.837 \\
0.799 \\
0.747 \\
0.714 \\
0.657\end{array}$ & 0.928 & 0.969 \\
\hline 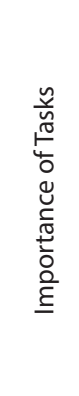 & $\begin{array}{l}\text { Q.26 Importance in dealing with restlessness and crying } \\
\text { Q.5 Importance in calming down } \\
\text { Q.29 Importance in understanding infant signs } \\
\text { Q.17 Importance in diaper change } \\
\text { Q.2 Importance in bath } \\
\text { Q.8 Importance in feeding } \\
\text { Q.23 Importance in safe transportation } \\
\text { Q.11 Importance in providing infant health care } \\
\text { Q.14 Importance in safe sleeping methods } \\
\text { Q.35 Importance in caring with a partner as a team } \\
\text { Q.20 Importance in resuscitation } \\
\text { Q.32 Importance in the adaptation to the infant }\end{array}$ & $\begin{array}{l}0.863 \\
0.823 \\
0.759\end{array}$ & $\begin{array}{l}0.842 \\
0.746 \\
0.726\end{array}$ & $\begin{array}{l}0.726 \\
0.804 \\
0.793 \\
0.730\end{array}$ & $\begin{array}{l}0.716 \\
0.689 \\
0.533\end{array}$ \\
\hline 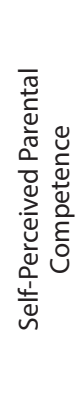 & $\begin{array}{l}\text { Q.3 Success in bath } \\
\text { Q.21 Success in resuscitation } \\
\text { Q.27 Success in dealing with restlessness and crying } \\
\text { Q.12 Success in providing infant health care } \\
\text { Q.24 Success in safe transportation } \\
\text { Q.18 Success in diaper change } \\
\text { Q.9 Success in feeding } \\
\text { Q.15 Success in safe sleeping methods } \\
\text { Q.6 Success in calming down } \\
\text { Q.36 Success in caring for with a partner as a team } \\
\text { Q.30 Success in understanding infant signs } \\
\text { Q.33 Success in adaptation to the infant }\end{array}$ & $\begin{array}{l}0.776 \\
0.776 \\
0.765 \\
0.747 \\
0.729 \\
0.701 \\
0.598\end{array}$ & $\begin{array}{l}0.929 \\
0.776\end{array}$ & $\begin{array}{l}0.766 \\
0.766 \\
0.754\end{array}$ & 0.892 \\
\hline
\end{tabular}

Note: Extraction method: Principal Component Analysis. Rotation Method: Varimax with Kaiser normalization. *Q=Question. 


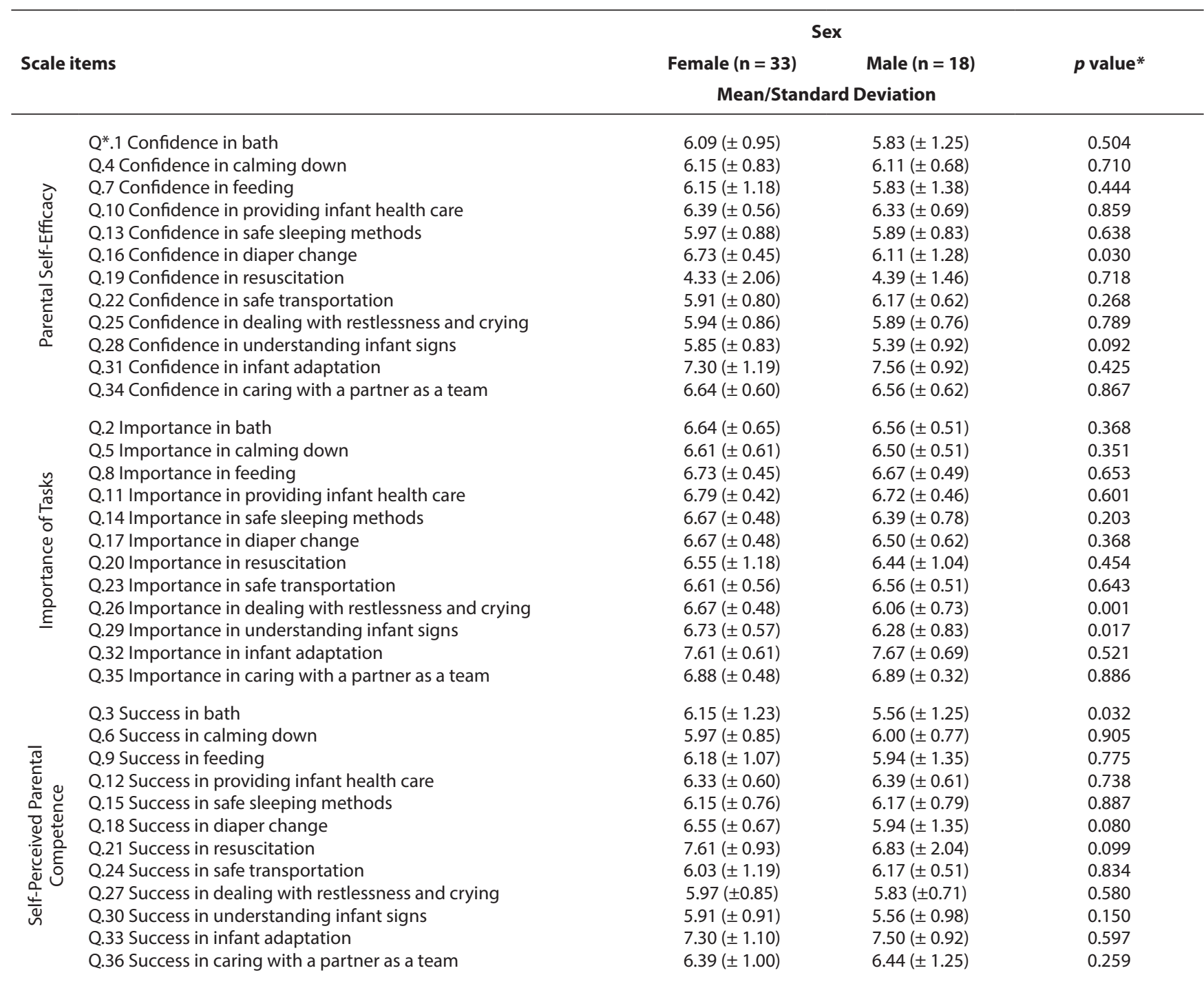

\section{DISCUSSION}

Cronbach's alpha calculation for the scale validated in Brazilian Portuguese indicated good internal consistency of the instrument as a whole; and the analysis by subscale produced values showing low to moderate consistency. The researchers believe that these values may be the result of using a small sample, as observed in this study, which should be larger in further studies.

In the original Preterm Parenting \& Self-Efficacy Checklist ${ }^{(11)}$, Cronbach's alpha was calculated for only two subscales: 0.750 in parental self-efficacy, indicating acceptable consistency; and 0.560 in self-perceived parental competence, indicating a low consistency.

Regarding the stability of the instrument validated in the testretest, the ICC presented stability over time in most questions. However, some questions produced lower values than those recommended. This finding can be expected, since the Preterm Parenting \& Self-Efficacy Checklist is a subjective instrument that measures a variable that changes over time, which is the perception of parental capacity in premature infant care after hospital discharge.
Studies on the experience of parents show that trust and ability in care change every day in everyday routine and provision of care to the infant ${ }^{(18-20)}$.

The participants of this study are similar to those of the original study, regarding the socio-demographic characteristics of parents and children, gestational age and birth weight; differing only in sample size. However, the sample size was smaller.

In the analysis by subscale of construct validity using factor analysis, four factors were found that explained cumulative variance showing it has an acceptable internal structure of grouped questions.

In some questions of this study, the load factor presented values lower than 0.60 (0.533 to 0.598$)$, below the value adopted in this study. Then, these values should be reviewed in other applications - the questions are related to Q.9-success in feeding the premature infant; Q.22-confidence in safe transportation; Q.26-importance in dealing with restlessness and crying of the newborn; and Q.33-success in infant adaptation. However values above 0.50 are considered statistically significant ${ }^{(21)}$. 
In the analysis of psychometric properties, the largest number was of mothers, just like the sample from the original study ${ }^{(11)}$, which had 120 (77.4\%) mothers. This percentage can be attributed to extended hospitalization period of premature infants, which was also seen in other studies ${ }^{(22-24)}$ that report lower presence of fathers during hospitalization due to their responsibilities at work, their role of providers and family support.

In studies ${ }^{(23-24)}$ on the importance of the father figure at the discharge of the premature infant of the NICU, the authors verified that the father shows fears and anxieties regarding child care at home and the exercise of his parenthood. Thus, the authors recommend investments should be made to go beyond theoretical recommendations and include the father as an integral part of the discharge process, someone who is affected by preterm birth and builds parenthood in a public context of the neonatal unit.

The results of the clinical application of Preterm Parenting \& Self-Efficacy Checklist - Version 3 identified that perceiving the ability to change a diaper of a premature infant; perceiving the importance of understanding the infant signs; dealing with restlessness and crying; and feel successful in the task of giving a bath were statistically significant related with the maternal figure. Such aspects about the development of parenting in the neonatal unit were evidenced in other investigations ${ }^{(25-26)}$, reinforcing that mothers who are prepared for hospital discharge show reduced anxiety and increased self-confidence in providing care to premature infants at home.

A study ${ }^{(27)}$ that evaluated levels of stress in mothers at the moment of discharge identified three potential stressors: the complex NICU environment; the appearance of preterm infants; and changes in parental role. Combined with these stressors at discharge, the infant's own prematurity can increase the economic demands and other requirements associated with the social cost of treatment and recovery. These are factors that may have an impact on the mother's learning and infant readiness for the discharge and transition from hospital to home ${ }^{(27-29)}$.

The most fragile aspects presented by parents in the Preterm Parenting \& Self-Efficacy Checklist - Version 3 regarding the success in performing tasks with their preterm infants were related to diaper change, in which the parents felt they were just'average'; dealing with infant restlessness and crying when they felt'a little successful' only; caring for their husband when they felt 'rarely successful'; understanding the infant signs when they felt 'not successful at all'; and providing health and medical care such as administering medication and taking the infant to medical appointments when they felt 'a little successful'.
The measurement of parental self-efficacy in care presented areas that should be reinforced by the health team in the process of hospital discharge with the family, as they may increase the level of stress experienced after hospital discharge.

Then, after all adaptation stages, the instrument was named Preterm Parenting \& Self-Efficacy Checklist - Brazilian Version.

\section{Study limitations}

This study was conducted in a private institution, whose socio-demographic characteristics of the participants represent a portion of the Brazilian population. Therefore, it should be used in different health care settings, with other portions of the target population of the Preterm Parenting \& Self-Efficacy Checklist Brazilian Version.

\section{Contribution to nursing, health or public policy}

The Preterm Parenting \& Self-Efficacy Checklist - Brazilian Version has the potential to be implemented in the nursing practice in outpatient units, follow-up programs for the infant at risk, and for nurses from the Family Health Strategy, as a measure to evaluate parent preparation for preterm infant care at home.

The creation of hospital discharge guidelines is recommended, specifically for parents of preterm infants and their families to insert them in care and improve their perception of self-efficacy and parental competence. Besides that, parent training should be carried out as to consider their individualities and potentialities.

\section{CONCLUSION}

The analysis of the psychometric properties of the Preterm Parenting \& Self-Efficacy Checklist - Brazilian Version of the target population showed good internal consistency, satisfactory stability in some questions over time and good reliability. It presented load factors that allowed the maintenance of all questions in the adapted instrument. The Preterm Parenting \& Self-Efficacy Checklist - Brazilian Version kept the properties of the original instrument.

When using the Preterm Parenting \& Self-Efficacy Checklist Brazilian Version in future studies, the sample should be larger to evaluate the psychometric properties of other populations and reduce the Likert scale items from seven points to five points (1Not confident at all, 2-Insecure, 3-A little confident, 4-Confident, 5 -Very confident).

\section{REFERENCES}

1. Melnyk BM, Oswalt KL, Sidora-Arcoleo K. Validation and psychometric properties of the neonatal intensive care unit parental beliefs scale. Nurs Res. 2014;63(2):105-15. doi: 10.1097/NNR.0000000000000023

2. Busse M, Stromgren K, Thorngate L, Thomas KA. Parents' responses to stress in the neonatal intensive care unit. Crit Care Nurse. 2013;33(4):52-9. doi: $10.4037 / \mathrm{ccn} 2013715$

3. Kruel CS, Lopes RCS. Transição para a parentalidade no contexto de cardiopatia congênita do bebê. Psic Teor Pesq. 2012;28(1):35-43. doi: 10.1590/S0102-37722012000100005

4. Larsson C, Wågström U, Normann E, Blomqvist YT. Parents experiences of discharge readiness from a Swedish neonatal intensive care unit. 
Nurs Open. 2017;4(2):90-5. doi: 10.1002/nop2.71

5. Osorio-Galeano SP, Ochoa-Marín SC, Semenic S. Preparing for post-discharge care of premature infants: experiences of parents. Investig Educ Enferm. 2017;35(1):100-8. doi: 10.17533/udea.iee.v35n1a12

6. Feeley N, Sherrad K, Waitzer E, Boisvert L. The father at the bedside: patterns of involvement in the NICU. J Perinat Neonatal Nurs. 2013;27(1):72-80. doi: 10.1097/JPN.0b013e31827fb415

7. Turner M, Winefield $\mathrm{H}$, Chur-Hansen A. The emotional experiences and supports for parents with babies in a neonatal nursery. Adv Neonatal Care. 2013;13(6):438-46. doi: 10.1097/ANC.0000000000000030

8. Raffray M, Semenic S, Osorio-Galeano S, Ochoa-Marín SC. Barriers and facilitators to preparing families with premature infants for discharge home from the neonatal unit: perceptions of health care providers. Invest Educ Enferm. 2014;32(3):379-92. doi: 10.17533/udea.iee.v32n3a03

9. Bandura A. Social cognitive theory of self-regulation. Organ Behav Hum Decis Process. 1991;50(2):248-87. doi: 10.1016/0749-5978(91)90022-L

10. Črnčec R, Barnett B, Matthey S. Review of scales of parenting confidence. J Nurs Meas. 2010;18(3):210-40. doi: 10.1891/1061-3749.18.3.210

11. Pennell C, Whittingham K, Boyd R, Sanders M, Colditz P. Prematurity and parental self-efficacy: the Preterm Parenting \& Self-Efficacy Checklist. Infant Behav Dev. 2012;35(4):678-88. doi: 10.1016/j.infbeh.2012.07.009

12. Beaton D, Bombardier C, Guillemin F, Ferraz MB. Recommendations for the cross-cultural adaptation of the DASH \& QuickDASH outcome measures [Internet]. Toronto: Institute for Work \& Health; 2002 [cited 2016 Aug 31]. Available from: http://www.dash.iwh.on.ca/sites/dash/ files/downloads/cross_cultural_adaptation_2007.pdf

13. Alexandre NMC, Gallasch CH, Lima MHM, Rodrigues RCM. Reliability in the development and evaluation of measurement instruments in the health field. Rev Eletr Enf. 2013;15(3):802-9. doi: 10.5216/ree.v15i3.20776

14. Fehring RJ. The Fehring model. In: Carroll-Johnson RM, Paquette M, editors. Classification of nursing diagnoses: proceedings of the Tenth Conference. Philadelphia: Lippincott; 1994. p. 55-62.

15. Gjersing L, Caplehorn JRM, Clausen T. Cross-cultural adaptation of research instruments: language, setting, time and statistical considerations. BMC Med Res Methodol. 2010;10:13. doi: 10.1186/1471-2288-10-13

16. Figueiredo Filho DB, Silva Jr JA. Visão além do alcance: uma introdução à análise fatorial. Opin Publica. 2010;16(1):160-85. doi: 10.1590/ S0104-62762010000100007

17. Siegel S, Castellan Jr NJ. Estatística não-paramétrica para ciências do comportamento. Porto Alegre: Artmed; 2006.

18. Magela MF, Lima FET, Matias EO, Siqueira AEOB, Magalhães FJ. Humanized assistance to the newborn at risk: implementation of the first stage of the kanagaroo method. J Nurs UFPE On Line. 2015;9(Suppl 10):1602-7. doi: 10.5205/reuol.8463-73861-2-SM.0910sup201529

19. Hamelin-Brabant L, Montigny F, Roch G, Deshaies M, Mbourou-Azizah G, Silva RB, et al. Vulnérabilité périnatale et soutien social en période postnatale: une revue de la littérature. Santé Publique. 2015;27(1):27-37. doi: 10.3917/spub.151.0027

20. Porat-Zyman G, Taubman-Ben-Ari O, Spielman V. Dyadic transition to parenthood: a longitudinal assessment of personal growth among parents of pre- and full-term infants. Stress Health. 2017;33(1):24-34. doi: 10.1002/smi.2669

21. Hair JF, Black WC, Babin BJ, Anderson RE, Tatham RL. Análise multivariada de dados. Porto Alegre: Bookman; 2009.

22. Kadivar M, Mozafarinia SM. Supporting fathers in a NICU: effects of the HUG Your Baby program on fathers' understanding of preterm infant behavior. J Perinat Educ. 2013;22(2):113-9. doi: 10.1891/1058-1243.22.2.113

23. Marski BSL, Custodio N, Abreu FCP, Melo DF, Wernet M. Hospital discharge of prematures newborns: the father's experience. Rev Bras Enferm [Internet]. 2016;69(2):202-9. doi: 10.1590/0034-7167.2016690203i

24. Montigny F, Lacharité C, Amyot É. The transition to fatherhood: the role of formal and informal support structures during the post-partum period. Texto Contexto Enferm. 2006;15(4):601-9. doi: 10.1590/S0104-07072006000400008

25. Fertonani HP, Pires DEP, Biff D, Scherer MDA. The health care model: concepts and challenges for primary care in Brazil. Ciênc Saúde Colet. 2015;20(6):1869-78. doi: 10.1590/1413-81232015206.13272014

26. Frota MA, Silva PFR, Moraes SR, Martins EMCS, Chaves EMC, Silva CAB. Hospital and care of the premature newborn at home: maternal experiences. Esc Anna Nery. 2013;17(2):277-83. doi: 10.1590/S1414-81452013000200011

27. Alcântara KL, Brito LLMS, Costa DVS, Façanha APM, Ximenes LB, Dodt RCM. Family guidelines needed for a safe hospital of the premature newborn: integrative review. J Nurs UFPE On Line. 2017;11(2):645-55. doi: 10.5205/reuol.10263-91568-1-RV.1102201720

28. Garfield CF, Lee YS, Kim HN, Rutsohn J, Kahn JY, Mustanski B, et al. Supporting parents of premature infants transitioning from the NICU to home: a pilot randomized control trial of a smartphone application. Internet Interv. 2016;4(2):131-7. doi: 10.1016/j.invent.2016.05.004

29. Souza SR, Dupas G, Balieiro MMFG. Cultural adaptation and validation for the Portuguese language of the Parental Stress Scale: Neonatal Intensive Care Unit (PSS:NICU). Acta Paul Enferm. 2012;25(2):171-6. doi: 10.1590/S0103-21002012000200003 